\title{
Literature Review Based on Corporate Performance
}

\section{Caiyun Ouyang}

School of Management, Jinan University, Guangzhou, China

Email: ouyangcy_1995@163.com

How to cite this paper: Ouyang, C. Y. (2020). Literature Review Based on Corporate Performance. Open Journal of Social Sciences, 8, 616-631.

https://doi.org/10.4236/jss.2020.84044

Received: March 23, 2020

Accepted: April 27, 2020

Published: April 30, 2020

Copyright $\odot 2020$ by author(s) and Scientific Research Publishing Inc. This work is licensed under the Creative Commons Attribution International License (CC BY 4.0).

http://creativecommons.org/licenses/by/4.0/ (c) (i) Open Access

\begin{abstract}
With the development and continuous improvement of China's capital market, the operating performance of listed companies is getting more and more attention from its different stakeholders. Through collating the research literature related to corporate performance at home and abroad from 2015 to 2018, this paper finds that the research focuses on domestic and foreign literature are mostly different, and foreign research focuses on corporate performance evaluation and goal setting, while domestic research focuses more on policy, background, corporate strategy, and characteristics of the business itself. But both domestically and abroad, the relationship between human resources and corporate performance has been discussed. This article reviews the literature at home and abroad, and points out several issues that need attention in this field in the future.
\end{abstract}

\section{Keywords}

Enterprise Performance, Performance Management, Performance Evaluation

\section{Introduction}

Enterprise performance is a very important issue involving many aspects. From a micro perspective, the quality of an enterprise's operations involves not only the interests of its owners, but also the interests of stakeholders such as creditors and employees. From a macro perspective, the overall operating performance of a country's enterprises is a key factor in determining a country's international economic status. In recent years, scholars have carried out a lot of research around corporate performance in order to find more effective ways to improve corporate performance. Over time, scholars' research on corporate performance has become increasingly divergent, and fewer and fewer people have paid attention. However, the practical world's focus on corporate performance has not di- 
minished, and how to improve corporate performance is still one of the problems that managers need to solve urgently. This article reviews the literature on corporate performance in recent years with a view to providing useful clues for further research in this area.

\section{Corporate Performance Overview}

This chapter mainly introduces concepts related to corporate performance, such as the definition and development of corporate performance, the origin of corporate performance management, and how to evaluate corporate performance.

\subsection{Enterprise Performance}

In the book "Financial Management" published by Zhou Guangguo and others in 2001, firm performance (Firm Performance) refers to the operating efficiency and performance of the company during a certain period of operation. The level of enterprise operating efficiency is mainly reflected in profitability, asset operation level, debt repayment ability and subsequent development ability. The performance of the operator is mainly reflected by the results and contributions made by the operator to the operation, growth and development of the enterprise in the process of managing the enterprise. Bates and Holton point out: "Performance is a multidimensional construct, and the results are different depending on the measured factors" (Michael Armstrong, Angela Barony, 1998). Schneider (1986) believes that the performance management system should be a complete cycle, including measurement and standardization, contract formation, planning, supervision, and assistance. To sum up, performance management is based on the premise of a complete system and is interconnected with many factors. Therefore, performance is a collective term of performance and efficien$c y$, including the two meanings of the efficiency of the activity process and the result of the activity. At present, the general understanding of enterprise performance is that enterprise performance refers to the amount of output of a company under certain input conditions, or the net output of unit input.

\subsection{Enterprise Performance Management}

Enterprise performance is the input-output situation of a company during a certain period of operation. The enterprise must hope to obtain the maximum output with the minimum input, and thus derive performance management. According to Longman's dictionary, performance management is "the act of performing or the state of being performed", that is, the act or progress of execution. Therefore, performance management is a process-a continuous cycle of performance planning, performance counseling and communication, performance evaluation and evaluation, application of performance results, and improvement of performance targets for managers and employees at all levels to achieve organizational goals. The purpose of performance management is to continuously improve the performance of individuals, departments and organi- 
zations. The object is people, but people have thoughts and emotions, and they will cause fluctuations in performance. Therefore, performance management is the most difficult of all human resource management and enterprise management. Yes, in the 2006 World Economic Association assessment, performance management was ranked as the most difficult management problem.

\subsection{Enterprise Performance Evaluation}

At the same time, corporate performance, as a result of a certain period of time, is indispensable for evaluation. And different types of enterprises are usually not completely comparable, and the results obtained by different types of enterprises need to be evaluated with different standards. Therefore, the performance evaluation of enterprises (Performance Valuation) mainly refers to the evaluation subject according to a specific evaluation purpose. An act of objectively evaluating the performance and development of a company over a period of time by using certain indicators, standards, and methods. In the evaluation of enterprise performance, the evaluation subject and evaluation purpose are the starting point, the indicators, standards and methods are the means, and the performance and operation of the enterprise constitute the object of evaluation.

The development of evaluation indicators such as the Economic Value Added (Balanced Scorecard) and Balanced Scorecard is groundbreaking for the performance evaluation system. In order to better adapt to the rapidly developing modern economic system, a large number of scholars have proposed many new enterprise performance evaluation systems based on the original indicators. Gong Qiaoli advocates the establishment of an enterprise evaluation index system based on performance budget management, including economic benefit indicators and social benefit indicators. Based on the stakeholder theory, Li Pingli studied the interest protection mechanisms of different stakeholders and established a stakeholder model for evaluating performance of operators. Feng Lixia took EVA as the core indicator of the performance evaluation index system, and used the principle of balanced scorecard to interconnect a series of major procedures closely related to the creation of EVA to establish a pyramid-shaped performance evaluation system. Yang Zongchang and Xu Bo constructed a performance evaluation system starting from interest, income tax, depreciation, and amortization before profit. Zhu Zhilong and others borrowed from the basic structure of the balanced scorecard and the "Detailed Operational Performance Evaluation Rules" to construct a performance evaluation index system for listed companies that consists of a basic index system, a revised index system, and an evaluation index system.

\section{Summary of Foreign Enterprise Performance Research}

Foreign academic circles have more divergent concerns about corporate performance, including human resources and corporate performance, investor behavior, market price efficiency and corporate performance, goal setting and cor- 
porate performance, management control systems and corporate performance, accounting records and corporate performance, companies Persistence of performance, etc.

\subsection{Abbreviations and Acronyms}

Since the 1990s, human resources have gradually become an important source of corporate competitive advantage. As an important part of human resources, managers, especially senior managers, play an indispensable core leadership role in modern organizational decision-making.

Hsu, Novoselov, and Wang (2017) believe that overly confident CEOs are more willing to initiate investment projects that require experimentation, but often delay the response to bad news when the project is not implemented as planned. Accounting robustness accelerates the perception of bad news and spreads it to gatekeepers, making it more likely that CEOs will recognize problems earlier and start looking for solutions. Therefore, companies with overconfidence in CEO traits and accounting robustness should perform better. Their empirical tests confirm this prediction: Companies that adopt conservatives and run by overconfident CEOs often show better cash flow. Its findings apply to a variety of situations, including market response to acquisitions, downside cash flow risks, and analyst following. In addition, the joint positive effect of CEO self-confidence and accounting conservatism on corporate performance is stronger in highly uncertain environments and in companies facing less stringent financing constraints, which is consistent with theoretical predictions.

In addition to studying the personality characteristics of executives, there are also a large number of empirical studies examining the role of executive compensation in easing the agency conflict between executives and shareholders, but ignoring the importance of inter-relationships and synergies within the management team. In this regard, more and more executive compensation studies have adopted a multi-agent perspective, treating senior management as a team rather than isolated individuals. However, most of the empirical research on team-based contract design has focused on the impact of the distribution of executive compensation levels. And Robert et al. (2016) provided new insights into design based on team incentives, which is reflected in the distribution of cross-management compensation performance sensitivity (PPS). They investigated the relationship between managers and company performance and controlled the distribution of pay levels. Their research found that there is a critical level of PPS dispersion. When PPS dispersion is lower or higher than this critical level, company performance will deteriorate. This indicates that corporate performance is maximized with the internal optimal PPS dispersion. The results also show that the PPS dispersion contains permanent and temporary components. They speculate that the temporary component reflects the best discrete deviation from the regulatory cost, which inhibits the board from immediately rebuilding the optimal level. Consistent with the board's limited process of adjusting the bias only to the optimal level, they documented any close to $70 \%$ of 
the company's actual PPS dispersion over the next year. Finally, cross-sectional analysis shows that the detrimental effects of deviations from optimal PPS dispersion decrease during team tenure, increasing as teamwork and coordination become more important to business performance.

In recent years, regulators intend to improve the link between CEO compensation and company performance, and the implementation of performance stock options (PVSO) will help reduce agency behavior between shareholders and management. But the literature shows that the vision is good and the results are not satisfactory. The results of Abernethy, Kuang, and Qin (2015) indicate that strong CEOs can negate certain beneficial effects of PVSO by influencing adoption and selection of performance targets. They investigate whether the power of the CEO influences the company's decision to change its compensation system in response to regulatory and public pressure, and evaluates whether the power of the CEO influences the choice of performance indicators to minimize the impact of these reforms on their wealth. They looked at one component of CEO compensation, namely the use of the PVSO program, and found that companies with strong CEOs added less of an additional challenge to the initial PVSO given to their CEO. These companies also seem to have adopted the PVSO program early and are more likely to do so in the face of public outrage over executive compensation. The findings suggest that strong CEOs are trying to calm public anger by adopting PVSO quickly, but early adoption of PVSO does not seem to be the best strategy for increasing shareholder value.

\subsection{Investor Behavior, Market Price Efficiency and Corporate Performance}

A persistent question in financial reporting is whether and how a company's performance ("return indicator") prominently measures investor behavior and market price efficiency Elliott et al. (2015). In the laboratory market, test the impact of important income indicators on investor information search, belief in value, transaction quotes, and market price efficiency. These indicators have some ways of combining continuous and temporary elements. They found that the inclusion of temporary factors in important yield indicators led traders to search for unnecessary further information about these factors and overestimate their impact on basic values. Conversely, displaying permanent elements in revenue alone will increase the accuracy of traders' valuations. Price usually reflects the trader's belief in the value of the business, and it is most effective when instantaneous factors are completely excluded from the earnings indicator. Their research helps to study the significant impact of financial reports, including temporary factors in important income indicators that can lead to inefficient information search and beliefs about value bias that can cumulatively affect market prices. They also contribute to the research of the experimental market by showing that redundant disclosure is not always beneficial; excessive redundant disclosure of surplus factors can have a negative impact on investor behavior and market efficiency in particular. 


\subsection{Goals Setting and Corporate Performance}

Although goal setting is important for companies, previous research has rarely provided purposeful uses and minimal impact (Anderson, Dekker and Sedatole, 2010; ttner and Larcker, 2001; Libby and Lindsay, 2010). Although some studies provide mixed evidence of performance results on target difficulty levels, studies have shown that setting difficult targets can improve performance, but empirical evidence from field research is complex and ambiguous. To explain this ambiguity, Arnold and Artz (2015) introduced and analyzed the target flexibility of companies in adjusting their goals during the year. They believe that target flexibility is related to target difficulty and company performance in the field, so it can significantly promote understanding of their relationships. Their review of surveys and archival data from 97 companies supports our predictions. They find that the difficulty of business unit goals has a direct positive impact, but has an indirect negative impact on business performance, which is partially regulated by the target flexibility of the business. In addition, they found that the main purpose of planning and coordinating goals is to reduce performance impact (as opposed to performance evaluation). Their findings may help explain mixed field research evidence on target difficulty effects.

\subsection{Management Control System and Enterprise Performance}

Although recent case studies detail how managers can balance competitive priorities through MCS (Cardinal et al., 2004; Jørgensen and Messner, 2009; Mundy, 2010), the balance effect between control levers has not been formally tested. Bedford (2015) examined the use of management control systems (MCS) across different innovation models and their impact on corporate performance. Specifically, this study used Simmons' control framework leverage to investigate how senior managers are trying to balance exploration and mining at the same time, which puts conflicting requirements on companies. Using data collected from a survey of 400 executives at 400 companies, the study showed that patterns of use and interdependence among control levers related to enhanced performance depend on innovation models. The findings suggest that control leverage is related to the independence of companies specializing in exploration or development, suggesting that leverage in these contexts complements rather than supplements control. However, for two independent companies, diagnostic and interactive leverage have shown an interdependent effect on performance. In addition, some evidence suggests that the combination and balanced use of these levers can help generate the dynamic tensions necessary to manage conflicting innovation models.

\subsection{Corporate Performance and Accounting Records}

Yang (2017) investigated defensive and confident impression management strategies and the impact of company performance on accounting records by investigating FTSE 100 index companies' earnings disclosure on Twitter. Social 
media has become a mainstream place for organizations to present themselves because it provides businesses with more control over the image they intend to build and maintain through the communications and content they provide online. Our research results show that companies minimize the disclosure of negative information, but use various models and communication technologies to emphasize positive information. Specifically, improved performers are more willing to publish and disseminate revenue-related tweets to gain a higher degree of stakeholder engagement than during the period when performers declined. Based on these findings, we conclude that companies use social media opportunism to present their positive public image.

\subsection{Sustainability of Corporate Performance}

Economic theory suggests that the entire industry component of business performance is more durable than the specific component of the business. Early work by Brown and Ball (1967) and Magee (1974) found that a large part of the variability in corporate earnings can be explained by industry-level news. Lev (1983) reported a significant correlation between earnings persistence and economic factors, including product type and industry competition. Hui et al. (2016) provided evidence for this assertion. They found that industry-wide returns are more durable than company-specific returns. However, investors cannot fully distinguish the persistence of this differentiation, because when predicting earnings a year ago, stock prices weighted the two earnings components similarly. They found that these effects were partly due to the persistence of industry-wide disparities in returns when homogeneous industries or huge commercial shocks are not recognized by the market. Finally, the research results show that industry-wide cash flows are the most lasting component of earnings, and company-specific accrued profits are the least durable, suggesting that economic fundamentals and accounting structure are common information about the company's future earnings. However, the market incorrectly priced these components, which greatly underestimated the sustainability of cash flow across the industry and overemphasized the sustainability of company-specific accruals.

\section{Summary of Domestic Enterprise Performance Research}

Compared with foreign academic circles, the domestic academic circles pay more attention to corporate performance. They all focus on the relationship between human resources and corporate performance. But in addition, the domestic academic community pays more attention to the impact of national policies, corporate strategies, venture capital institutions and family-owned enterprises on corporate performance, and the research direction has more Chinese characteristics.

\subsection{Human Resources and Corporate Performance}

In the past three years, domestic research on human resources and corporate 
performance has shown a downward trend. The publication date of the literature is basically in 2015. Explore the characteristics of executives, the relationship between employees and organizations, and compare the incentive effects of executives and employees to explore how Improve business performance.

Hambrick et al. (1993) believe that the CEO has the individual characteristics of changing the status quo of the organization and seeking new institutional systems and strategic directions. As a result, CEOs with openness can reduce organizational strategic inertia. Lian and $\mathrm{He}$ (2015) analyzed the effect mechanism of CEO openness on strategic inertia and organizational performance from the theoretical and empirical perspectives, and obtained the following research conclusions: First, the higher the degree of CEO openness, the more the organization tends to adopt adaptation The environment's dynamic resource allocation strategy, so the degree of strategic inertia of the organization is lower. Second, the degree of ownership and autonomy of the CEO plays a significant role in regulating the relationship between its openness and organizational inertia, that is, the CEO holds shares The higher the level, the stronger the motivation of the open CEO to maintain the status quo of the organization's strategy, and the higher the managerial autonomy possessed by the CEO, the more inclined to break the strategic status of the organization; The relationship between inertia also plays a significant moderating role. The CEO of a state-owned enterprise has a smaller degree of negative impact on organizational inertia than the CEO of a family company. Fourth, compared to a linear relationship the inverted $\mathrm{U}$-shape hypothesis is more helpful in explaining the relationship between strategic inertia and organizational performance. This document takes listed companies from 2003 to 2009 as a sample and uses empirical analysis methods to improve the research on CEO personality characteristics and also expand the research on strategic change.

Chen (2015) empirically tested the relationship between the background of private investors, speculative investment, and corporate performance, based on the sample survey data of private enterprises nationwide in 2012 from the United Front Work Department of the CPC Central Committee and other 4 departments. The study found that low-age, male private-sector funders with management experience, deputies to the National People's Congress and CPPCC members, tend to choose speculative investment strategies. In terms of the significant positive effect, the same rules apply to the private enterprise investor's management experience on net profit and sales, CCP status as net profit and net assets, and acting as a deputy to the National People's Congress and CPPCC member on net assets. In terms of significant negative effects, private enterprise funders with low and medium education qualifications and decision-making powers on important matters of the enterprise have shown net sales and net assets, and the performance of sales of private enterprise funders who are members of the $\mathrm{Na}$ tional People's Congress and members of the Chinese People's Political Consultative Conference and middle-educated private enterprises on sales The rules are the same. Speculative investment has significantly promoted the three perfor- 
mance indicators of the enterprise. The author also finds that the interaction between the background of private investor and speculative investment has different regulating effects on corporate performance. Having management experience and membership of the Communist Party of China has a significant positive regulatory effect on the company's net profit, net assets and sales. As a deputy to the National People's Congress and a member of the CPPCC, it has a significant negative regulatory effect on the company's net profit, net assets and sales. Middle-low age and low-education have a significant negative regulating effect on corporate net profit and sales, and men have a significant positive regulating effect on corporate net profit and net assets. The literature concludes these phenomena, summarizes the research on how to resolve investment risks from the perspective of the investor background of private enterprises, and discusses the research limitations and future research directions.

Compared with the research by Lian and He (2015), Jia et al. (2015) focused on the impact of the matching relationship between executive competence characteristics and corporate strategic orientation on corporate performance. The viewpoint of contingency theory tells us that there is no theory applicable to all scenarios (Chow, Huang and Liu, 2008; Van de Ven, Ganco and Hinings, 2013). Different strategic orientations require executives with corresponding competence characteristics and Matching, that is, in order to achieve the best results, the competence characteristics of executives need to be consistent with the strategic orientation of the enterprise, and this matching will promote the improvement of corporate performance. Jia et al. (2015) systematically analyzed the impact of the matching of executive competence and strategic orientation on corporate performance based on contingency theory. The author uses questionnaires to obtain data related to variables. In addition to the previous strategy guide vector table and corporate performance scale, the author also designed the executive competency scale. The research results show that there are three strategically oriented enterprises in China, namely cost-oriented, innovation-oriented, and quality-oriented, and different types of strategic orientation have different effects on corporate performance. Among them, innovation-oriented enterprises and quality-oriented enterprises. Enterprises have higher financial performance and human resource performance than cost-oriented enterprises. They also found that the matching of single-dimensional executive competence with different strategic orientations has a different impact on corporate performance. Among them, strategic awareness has a significant impact on the performance of each strategically-oriented enterprise, and organizational building capabilities have a quality-oriented and innovation-oriented nature. Enterprise performance has a significant impact. Quality literacy has a significant impact on the performance of quality-oriented enterprises and the human resource performance of innovation-oriented enterprises, while insight only has a significant impact on the human resource performance of quality-oriented and innovation-oriented enterprises; Multi-dimensional executive competence characteristics and different strategic 
orientations have different effects on corporate performance. Executives' strategic consciousness matches cost-oriented and quality-oriented enterprises. Executives' strategic consciousness and organizational building capabilities are matched with innovation-oriented enterprises. Based on this, the author discusses the research results, expands and analyzes the differences in the impact of single-dimensional and multidimensional executive competence characteristics and strategic orientation on corporate performance, and gives management implications for the research results. This document is conducive to enriching and expanding the research on the matching relationship between executive competence, strategic orientation and corporate performance, and provides theoretical basis and empirical support for understanding and explaining the strategic decisions of Chinese enterprises.

Chen et al. (2015) realized that both executives and employees are corporate value creators, and both are important human resources that need to be motivated. Existing researches focus more on the research of executive incentives, less research on employee incentives, and the lack of research on combining the two. Existing studies have not paid enough attention to motivating executives or motivating employees, and the interaction between the two. Therefore, unlike Jia et al. (2015), who only studied the impact of executive competence on corporate performance, they used Chinese listed companies as a sample to analyze the comparison of their incentive effects on two types of human resources and their interaction. The study found that executive compensation and employee compensation are sensitive to corporate performance, and that executive compensation is significantly more sensitive than employees, indicating that both types of incentives have a positive effect on future performance growth. In addition, the positive effect of employees on the future performance of the company is higher than that of executives; the more synchronized the changes in the salary of executives and employees, the more positive the positive effect on future performance. This article first studied the comparison and interaction between the incentive effects of executives and employees, which has a profound impact on research in the field of incentives.

Coincidentally, Zhu et al. (2015) also explored the impact of employee organization relations on corporate performance. Employee-Organization Relationship (hereinafter referred to as EOR) is an important research topic in the field of organizational behavior, which reflects the status of a population relationship formed between employees and their organizations due to internal management. Zhu et al. (2015) based on Chinese cultural characteristics, proposed and verified that not only contractual and instrumental economic exchanges and social exchanges exist in the employee-organizational relationships of Chinese enterprises, but also similar family relationships that can reflect a high degree of employee-organization integration Exchange relationship. Through 3 independent empirical studies, a total of 1268 employees in more than 100 companies were surveyed, confirming the existence of the kinship-exchange relationship dimension in Chinese companies; the results of the hypothesis test showed that collec- 
tivism and the uncertainty of the work environment are similar An important antecedent of family exchange; similar family exchange has a higher explanatory power in employee emotional commitment, organizational loyalty, overall job performance, in-role behavior, and organizational citizenship than social exchange relationships; business performance negatively regulates family exchange to self Impact of Sacrifice and Suggestion Behavior-When the company's performance is not good, the higher the employee's similarity exchange, the more able to make self-sacrifice and suggestion behavior that is conducive to the enterprise.

\subsection{National Policies and Corporate Performance}

In order to accelerate the improvement and standardization of China's capital market, some national policies need to be adopted to regulate the market economy. The national policy is at a macro level and has a wide range of influences. It usually affects the micro behavior of enterprises and then affects corporate performance.

Lian et al. (2016) used the data of 1241 non-financial listed companies in China's A-share market, and measured the market performance of the company in terms of stock returns (specifically, buy and hold return), and examined economic stimulus policies. The impact of the financial crisis and the period of economic downturn after the withdrawal of the economic stimulus policy (referred to as the period of "downward economic pressure") on the performance of the company's performance, and then explore the impact of the financial crisis and the economic stimulus policies introduced in China on corporate microbehavior. The study found that: the market performance of enterprises during the financial crisis and the downward pressure of the economy showed a positive correlation, and this result exists only in industries supported by economic stimulus policies; economic stimulus policies have a bearing on the financial crisis and the downward pressure of the economy The impact of corporate performance correlation during the period is stronger in non-state-owned enterprises. In addition, the author finds that economic stimulus policies lead to companies with worse market performance during the financial crisis, and more financing and investment during economic stimulus, and stock price guidance is the possible formation mechanism. Finally, the author also found that there was a positive correlation between the market performance of companies during the financial crisis and the operating efficiency of the financial crisis, economic stimulus, and downward economic pressure. Therefore, the economic stimulus policy of the Chinese government to cope with the financial crisis may cause entrepreneurs to ignore the opportunity to learn from the experience of the financial crisis, thus failing to effectively adjust enterprises during the economic stimulus. This document is helpful for us to deeply understand the impact mechanism of macro policies on enterprises, and to provide certain policy recommendations for the country to formulate macro policies. 
The reform of split share structure is an important event in the history of the development of China's capital market, which aims to solve the historical problems of "shared shares with different rights and different shares with different prices" in listed companies. Chen and Huang (2016) Aimed at the event of profound changes in the capital market in China, based on the perspective of economic consequences, and using data from listed companies from 2001 to 2010, they examined the changes in the company's equity hierarchy before and after the reform Impact on business performance. Their research found that after the split share structure reform, with the reduction of agency conflicts between the controlling shareholder and other minority shareholders, the company's equity level has significantly decreased. Further analysis shows that due to the decrease in agency costs and the strengthening of management supervision, the company's performance after the share split reform has increased due to the reduction of equity levels. Finally, the author also finds that the effect of the split share structure reform on the company's equity level and operating performance is more significant in non-state-owned companies. This document affirms the role of the shareholding reform and advocates that the government should work hard to promote listed companies to establish a simple and clear structure of equity structure. While achieving improvements in corporate operating efficiency, it will better safeguard investor rights and interests and promote China The healthy development of the capital market.

\subsection{Corporate Strategy and Corporate Performance}

Corporate strategy and corporate performance are always important topics in the field of management accounting. Enterprise strategy includes development strategy, stable strategy, contraction strategy, merger and acquisition strategy, cost leadership strategy, differentiation strategy and concentration strategy. Michael Porter (1980) proposed the basic classification paradigm of competition strategy in the book "Competitive Strategy", which provided important theoretical basis for subsequent research. Therefore, Michael was also called "the father of competitive strategy".

Lei et al. (2015) supported the quarterly financial data of Shanghai enterprises, used confirmatory factor analysis to identify the type of competition strategy of the company, used the grey correlation analysis method to calculate the comprehensive strategic performance index, and used VAR model and impulse response function to analyze Tools to analyze the lag effect of competitive strategic performance. The research results show that the improvement of corporate performance lags behind the implementation of competitive strategy, and the performance of competitive strategy is lagging and sustainable. Compared with low-cost strategies, companies implementing differentiated strategies have more delayed and sustained performance, long. The literature takes into account the effects of strategic lag, collects long-term time data, and studies the continuity of performance response based on this, expanding the research on competitive 
strategy and corporate performance.

The vertical integration strategy is one of the developmental strategies. Its relationship with corporate performance has long been widely concerned by the academic community, and multi-perspective studies have been conducted, but only a unified conclusion has not been obtained. Wang and Wang (2016) used the data of China, Canada, and Australia from 2010 to 2014 to examine the performance of vertical integration of forestry listed companies in profitability and the unique role of industry heterogeneity. Research shows that whether a company adopts a vertically integrated business strategy will significantly affect its profitability, and this impact will vary widely across countries: the Chinese sample is negative, the Australian sample is positive, and the Canadian sample is not. Further analysis found that the reason behind the phenomenon of country differences is industry heterogeneity. Industry asset characteristics, product characteristics, operating characteristics, supply-demand relationships, and the external environment all affect the cost-benefit relationship of vertical integration, which in turn affects profitability. Therefore, enterprises should choose a vertical integration strategy suitable for their industry characteristics, and continuously optimize the value chain; the government should encourage efficient integration through industrial policy levers, and especially support technological innovation to improve the performance of the industry value chain. The contribution of this document lies in the author's comparison using data from multiple countries, taking forestry enterprises as an example, analyzing their existing problems, and then drawing the conclusion that the integration strategy should be combined with the characteristics of the enterprise itself.

\subsection{Venture Capital Institutions and Corporate Performance}

Dong et al. (2017) used Chinese SME board and GEM listed companies as research samples to analyze and test the impact of the basic management methods of venture capital institutions on the performance of entrepreneurial enterprises, and the adjustment mechanism of industry expertise and uncertainty on the above effects. The groundbreaking classification of venture management and venture capital management models explores and validates the matching relationship between the two. Their research results show that: 1) the value-added services provided by venture capital institutions have a significant positive impact on the performance of startups, and the higher the industry expertise of venture capital institutions, the stronger this impact; 2) venture capital institutions The impact of the implemented supervision and control on the performance of entrepreneurial enterprises is not significant, but when the uncertainty faced by entrepreneurial enterprises is higher, more supervision and control will have a negative impact on corporate performance; 3) venture capital management models and entrepreneurial enterprises There is a matching relationship between the types: the coaching management model works best when the venture capital institution has high industry expertise and the startup company faces low uncertainty; the venture capital institution has high industry expertise and 
the startup company faces In the case of high uncertainty, the service-enhanced management model has the best effect; in the case of venture capital institutions with low industry expertise and entrepreneurial enterprises facing low uncertainty, the control-enhanced management model has the best effect; Venture capital institutions with low industry expertise and start-ups face high uncertainty. What is different from theoretical expectations is stocking. Management was not significant statistically. This document ground breakingly studies the inherent management mechanism of venture capital institutions' involvement in venture capital to create value, and provides higher academic and practical value for venture capital theory and venture capital theory.

\subsection{Family Enterprises and Enterprise Performance}

In the past ten years, "family-owned enterprises" have sprung up in China's capital market and exerted increasingly important influence. Guojian Zhen et al. (2016) summarized and compared the important differences in corporate governance, capital operation, and group management of the three types of organizational forms: family-owned enterprises, non-family-type group-controlled enterprises, and independent (overall listed) enterprises. From 2003 to 2013, 274 family groups (including 770 members of A-share listed companies) were taken as research objects, and empirical analysis was performed on the differences in corporate performance of these three types of organizational forms. We found that, in general, family-owned enterprises performed the worst, followed by non-family-based group-controlled enterprises, and independent enterprises performed best. Moreover, the above organizational forms performed worse in the private sample. Finally, with the unique internal structure data of the family group, the relationship between the internal structural characteristics of the family group and the performance of member companies was empirically investigated for the first time, which provided an important perspective and empirical evidence for understanding the mechanism of the economic consequences of the enterprise group.

\section{Summary and Outlook}

In summary, in recent years, the number of literatures related to corporate performance has been decreasing year by year, and our blind spots in this field have been decreasing. From the Chinese and foreign literatures I reviewed, the common thing is that they all use human resources as a research point to explore the impact of human resource elements on corporate performance, because human resources have long been an important source of corporate competitive advantage, affecting at multiple levels, Business Performance. At the same time, human resources usually involve incentive mechanisms, which is also a hot topic in the field of management accounting research. Therefore, compared with other types of literature, there are much more literatures exploring human resources and corporate performance. The difference is that foreign literature focuses more on corporate performance evaluation and goal setting. Usually, the re- 
search point is small, but the research depth is large and seemingly irrelevant things, but they affect and restrict each other. Domestic journals are more focused on the policy background, corporate strategy, and characteristics of the enterprise itself. In addition, I found that the literature on corporate performance in China in the past three years has rarely used experimental research methods, most of which are empirical articles, and some also use survey research methods.

Compared with foreign language journals, domestic literature research is broader and more macroscopic. For example, research on national policies still has room for subdivision. At present, tax policy, accounting policy and innovation patent policy change frequently. Scholars can use this as a miracle to study the performance before and after the change and explore the contribution of national policy to corporate performance. Also, domestic literature also has relatively single indicators for measuring company performance. We can create more and more targeted indicators to measure company performance in combination with national conditions and the actual situation of enterprises. Therefore, there is still ample space for research on corporate performance. The author hopes that the combing and returning of this article can inspire later scholars to find new perspectives to explore corporate performance, find new ways to improve corporate performance, and enhance national economic strength.

\section{Acknowledgements}

On the completion of this thesis, I am very grateful to Mr. Bai Hua for his careful guidance and suggestions from the reviewers, so that my paper can be published.

\section{Conflicts of Interest}

The author declares no conflicts of interest regarding the publication of this paper.

\section{References}

Arnold, M. C., \& Artz, M. (2015). Target Difficulty, Target Flexibility, and Firm Performance: Evidence from Business Units' Targets. Accounting Organizations and Society, 40, 61-77. https://doi.org/10.1016/j.aos.2014.12.002

Bedford, D. S. (2015). Management Control Systems across Different Modes of Innovation: Implications for Firm Performance. Management Accounting Research, 28, 12-30. https://doi.org/10.1016/j.mar.2015.04.003

Chen, D. (2015). Background of Private Investors, Speculative Investment and Enterprise Performance. Management World, 97-119+187-188.

Chen, D. H., Fan, Z., \& Shen, Y. J. (2015). Executives and Employees: Comparison and Interaction of Motivation Effectiveness. Management World, 160-171.

Chen, X. Y., \& Huang, J. (2016). Reform of Share Ownership Structure, Equity Hierarchy and Corporate Performance. Accounting Research, 56-62+96.

Dong, J., Wang, J. P., Zhai, H. Y., \& Wang, L. (2017). Service or Monitoring: The Man- 
agement of Venture Capital by Venture Capital Institutions-A Perspective of Industry Expertise and Uncertainty. Management World, 82-103+187-188.

Elliott, W. B., Hobson, J. L., \& White, B. J. (2015). Earnings Metrics, Information Processing, and Price Efficiency in Laboratory Markets. Journal of Accounting Research, 53, 555-592. https://doi.org/10.1111/1475-679X.12080

Hambrick, D. C., Geletkanycz, M. A., \& Fredrickson, J. W. (1993). Top Executive Commitment to the Status Quo: Some Tests of Its Determinants. Strategic Management Journal, 14, 401-418. https://doi.org/10.1002/smj.4250140602

Hsu, C., Novoselov, K. E., \& Wang, R. C. (2017). Does Accounting Conservatism Mitigate the Shortcomings of CEO Overconfidence? Accounting Review, 92, 77-101. https://doi.org/10.2308/accr-51718

Hui, K. W., Nelson, K. K., \& Yeung, P. E. (2016). On the Persistence and Pricing of Industry-Wide and Firm-Specific Earnings, Cash Flows, and Accruals. Journal of Accounting and Economics, 61, 185-202. https://doi.org/10.1016/j.jacceco.2015.06.003

Jia, J. F., Tang, G. Y., Li, J. P., Wang, W. J., \& Shan, X. (2015). The Impact of the Matching of Executive Competence and Strategic Orientation on Corporate Performance. Management World, 120-132.

Lei, H., Wang, Y. N., Nie, S. S., \& Ouyang, L. P. (2015). Study on the Delay Effect of Competitive Strategy Performance Based on the Financial Performance Comprehensive Index. Accounting Research, 64-71+95.

Lian, L. S., Chen, C., \& Mi, C. L. (2016). Is It Possible to Have One President and One Wisdom after Eating?-Research on the Correlation of Corporate Performance under the Influence of Financial Crisis and Economic Stimulus Policies. World of Management, 111-126.

Lian, Y. L., \& He, X. G. (2015). CEO Openness, Strategic Inertia and Organizational Performance: An Empirical Analysis Based on Chinese Listed Companies. Journal of Management Sciences in China, 1-19.

Robert, B. M., Dai, Z. L., \& Zhang, W. N. (2016). Management Team Incentive: Dispersion and Firm Performance. Accounting Review, 91, 21-45. https://doi.org/10.2308/accr-51112

Wang, B., \& Wang, L. J. (2016). Vertical Integration, Industry Heterogeneity and Corporate Profitability: A Comparative Analysis Based on Sino-Canadian and Australian Listed Forestry Companies. Accounting Research, 70-76 + 96.

Zhu, S. L., Long, L. R., He, W., \& Wang, Z. J. (2015). Beyond Instrumental Exchange: Theoretical Construction and Empirical Study of Employee-Organizational Family Exchange Relationship in Chinese Enterprises. Management World, 160+187-188. 